\title{
Early Metabolic Flare in Squamous Cell Carcinoma after Chemotherapy is a Marker of Treatment Sensitivity In Vitro
}

\author{
Maria Bjurberg • Parisa Abedinpour • Eva Brun • \\ Bo Baldetorp • Per Borgström • Johan Wennerberg • \\ Elisabeth Kjellén
}

Received: 8 April 2010/Revised: 6 May 2010 /Accepted: 7 May 2010/Published online: 9 June 2010

(C) The Author(s) 2010. This article is published with open access at Springerlink.com

\begin{abstract}
Purpose Early metabolic response with a decrease in glucose demand after cytotoxic treatment has been reported to precede tumor volume shrinkage. However, preclinical studies report of a very early rise in metabolism, a flare, following treatment. To elucidate these observations, we performed an experimental study on early metabolic response with sequential analysis of metabolic changes.

Methods Three squamous cell carcinoma cell lines and one nontumorigenic cell line were exposed to cisplatin. The uptake of the fluorescent glucose analogue 2-NBDG was examined at days 1-6 using fluorescence microscopy. The relation between 2-NBDG-uptake and cell survival was evaluated.
\end{abstract}

M. Bjurberg and P. Abedinpour contributed equally to this work

M. Bjurberg $(\bowtie) \cdot$ E. Brun $\cdot$ E. Kjellén

Department of Oncology,

Lund University and Lund University Hospital,

22185 Lund, Sweden

e-mail: maria.bjurberg@med.lu.se

P. Abedinpour $\cdot$ P. Borgström

Vaccine Research Institute of San Diego,

San Diego, CA, USA

B. Baldetorp

Clinical Sciences, Department of Oncology, Lund University,

Lund, Sweden

J. Wennerberg

Department of Otorhinolaryngology and Head and Neck Surgery,

Lund University Hospital,

Lund, Sweden

E. Kjellén

Department of Radiation Sciences, Umeå University,

Umeå, Sweden
Results The tumor cells exhibited a high uptake of 2NBDG, whereas the uptake in the nonmalignant cells was low. The more cisplatin sensitive cell lines exhibited a more pronounced metabolic flare than the less sensitive cell line. Conclusion A metabolic flare was a very early sign of treatment response and potentially it could be used as an early marker of treatment sensitivity.

Keywords FDG-PET - NBDG · Flare · Fluorescence · Chemotherapy $\cdot$ Squamous cell carcinoma

\section{Introduction}

Positron emission tomography (PET) with 2-deoxy-2- $\left[{ }^{18} \mathrm{~F}\right]$ fluoro-D-glucose $\left(\left[{ }^{18} \mathrm{~F}\right] \mathrm{FDG}\right)$ as a tracer is a well-established method to visualize hypermetabolism in cancer. A number of clinical studies in different types of tumors evaluating changes in uptake and metabolism of $\left[{ }^{18} \mathrm{~F}\right] \mathrm{FDG}$ with PET within 1-3 weeks after initiated cytotoxic therapy have reported a decrease in glucose metabolism as an early sign of tumor response to therapy. It is observed before any decrease in actual tumor size as is seen, i.e., in head and neck cancer, Hodgkin lymphoma, esophageal cancer, and cervical cancer [1-4]. Experimentally, a rapid metabolic response has been demonstrated as by Spaepen et al. [5]. A transient metabolic flare resulting from an increase in tumor metabolism has been observed on sequential $\left[{ }^{18} \mathrm{~F}\right]$ FDG-PET scans $7-10$ days after initiating tamoxifen treatment for breast cancer $[6,7]$. The metabolic flare was in these studies associated with response to tamoxifen therapy, indicating that a metabolic flare reaction is of predictive value.

In the experimental setting, an early flare phenomenon following initiation of tumor treatment has been seen in 
vitro in xenograft models of testicular cancer and squamous cell cancer 1-5 days following initiation of chemotherapy [8-10]. The underlying mechanism of this early metabolic flare is not understood. The present study was carried out to examine early metabolic changes on the cellular level in tumor cell-lines originating from human squamous cell carcinomas in relation to sensitivity to cytotoxic treatment with cisplatin. To facilitate the investigation of the flare phenomenon, we used the fluorescent 2-deoxyglucose (DG) analogue 2-[N-(7-nitrobenz-2-oxa-1,3-diazol-4-yl)amino]2-deoxyglucose (2-NBDG). This fluorescent DG analogue has been demonstrated to provide an optical marker of glucose uptake enabling investigation on a cellular level and may also be easier to handle than radiolabeled FDG in the experimental setting $[11,12]$.

\section{Materials and methods}

\section{Chemicals}

The chemicals used in this study were of analytical grade. Cisplatin $(1 \mathrm{mg} / \mathrm{ml})$ was purchased from Sigma-Aldrich (St. Louis, Mo., USA). We used cisplatin in a clinically relevant dose of $10 \mu \mathrm{M}$ and in a high dose of $50 \mu \mathrm{M}$ in order to get an explicit tumor cell effect. The 2-NBDG was purchased from Invitrogen (Carlsbad, Calif., USA) and $10 \mu \mathrm{M}$ 2-NBDG was freshly made on the same day as the experiment using a low glucose solution of phosphate-buffered saline (PBS) containing 10-15\% Dulbecco's Modified Eagle Medium (DMEM) without fetal bovine serum (FBS).

\section{Cell cultures}

We used four in-house human cell lines originating from primary untreated tumors. Each cell line's degree of sensitivity to cisplatin was known before the experiment. The cell line LU-HNxSCC-7, originating from a moderately differentiated head and neck squamous cell carcinoma (HNSCC), is cisplatin sensitive. The cell line LUHNxSCC-24 originating from a well differentiated HNSCC is also sensitive to cisplatin, but the third tumorigenic cell line LU-CX-2 originating from a poorly differentiated SCC of the uterine cervix has a low sensitivity to cisplatin. Finally, a nontumorigenic cell line with fibroblasts from the LU-HNxSCC-24 cell line was used.

\section{Experimental design}

The cell lines were trypsinised, washed with PBS, replaced using DMEM and counted using an automated cell counter (Invitrogen Carlsbad, Calif., USA). Aliquots of 80,000 cells were transferred into flasks and the flasks were placed in a cell incubator at $37^{\circ} \mathrm{C}$ and $5 \% \mathrm{CO}_{2}$ overnight. The next day, denoted day 0 , the cells in six flasks were exposed to $10 \mu \mathrm{M}$ cisplatin, the cells in another six flasks were exposed to $50 \mu \mathrm{M}$ cisplatin and the cells in six flasks were left as untreated controls. All flasks were then incubated for $1 \mathrm{~h}$ at $37^{\circ} \mathrm{C}$ and $5 \% \mathrm{CO}_{2}$ atmosphere after which the medium containing cisplatin was removed and replaced with DMEM containing $10 \%$ FBS. The flasks were then returned to the cell incubator, where they were kept at $37^{\circ} \mathrm{C}$ and at $5 \% \mathrm{CO}_{2}$ until monitoring. At days 1, 3 and 6 after cisplatin exposure, the cells were monitored using fluorescence microscopy. For each time point, two flasks from the $10 \mu \mathrm{M}$ cisplatin group, two flasks from the $50 \mu \mathrm{M}$ cisplatin group and two flasks from the control group were observed. Before observation, all the cells including the controls were exposed to $10 \mu \mathrm{M} 2$ NBDG in PBS as described above. The cells were incubated at $37^{\circ} \mathrm{C}$ and $5 \% \mathrm{CO}_{2}$ for $1 \mathrm{~h}$, then washed with cold PBS twice, after which DMEM containing 10\% FBS was added prior to microscopy. The experiment was done in duplicate for each cell line.

\section{Real-time fluorescence microscopy}

The cell cultures were evaluated for fluorescence, morphology and survival. Fluorescence microscopy was performed using a Leitz Orthoplan Microscope equipped with epiilluminator and video-triggered stroboscopic illumination from a xenon arc (X-Strobe X400, PerkinElmer Salem, Mass., USA). A silicon intensified target camera (VE-1000SIT Dage-MTI, Michigan City, Ind., USA) was attached to the microscope. A Zeiss Achroplan 20X/0.5 W objective was used for capturing images. A DSP-200 image processor (Dage-MTI, Michigan City, Ind., USA) was used for image enhancement and the Win TV2000 (Hauppage ComputerWorks, Hauppage, N.Y., USA) software was used to capture images to a computer. The fluorescence intensity of the cells was obtained using a GFP filter set (Semrok, Rochester, N.Y., USA). Image analysis was performed using Image Pro Plus 6.2 (Media Cybernetics, Bethesda, Md., USA). We used the achroplan $20 \times$ objective, and the average fluorescence intensity was calculated in one field of observation as the number of pixels representing tumor cell area with intensity above backround level (which was chosen as 45 on an arbitrary gray-scale between 0 and 255) divided by the number of pixels representing the total tumor cell area. Electronic cell counting and analysis of cell survival was performed after observation by using a NucleoCounter (Chemothec, Allerød, Denmark).

Statistical analysis

Statistical analysis was performed using a statistical software package (SigmaStat, Jandel Scientific, USA) and 
involved both analysis of variance and multiple comparison tests. For all tests, $p$ values smaller than $5 \%$ were considered significant. Data was presented as mean \pm standard error of the mean (SEM).

\section{Flow cytometry}

The cells were stored at $-20^{\circ} \mathrm{C}$ until analysis. After thawing, centrifugation, removal of medium, and resuspension, the cells were stained with propridium iodide (PI). The samples were analyzed using a FACSCalibur flow cytometer (BD Biosciences, San Jose, Calif., USA) equipped with an argon ion laser. PI-stained cells were analyzed using an excitation wavelength of $488 \mathrm{~nm}$. The Cell Quest Pro software was used for data acquisition and analysis. The distribution of the cell cycle phases was determined by applying the ModFit Lt 3.1 software (Verity Software House, Topsham, Me., USA).

\section{Results}

\section{Uptake of 2-NBDG}

For all of the cell lines, the uptake of 2-NBDG was well visualized and heterogeneous within the samples. The benign cell line exhibited a low uptake of 2-NBDG throughout the experiment. For the tumor cells exposed to cisplatin, the uptake of 2-NBDG increased over time (days $1-6)$, as opposed to the untreated control cells, where the uptake remained constant at a moderately elevated level. The level of 2-NBDG uptake was correlated to the previously known sensitivity to cisplatin, with the more sensitive cell line showing the highest 2-NBDG uptake. We also observed that the higher the dose of cisplatin, the higher the uptake of 2-NBDG. The difference in 2-NBDG uptake was present already at day 1 , in the cell line most sensitive to cisplatin, and from day 3 in both of the other tumor cell lines (Fig. 1). Visually, the early increase in uptake of 2-NBDG was most pronounced in pre-apoptotic cells, exhibiting characteristically rounded shapes and cytoplasmic vacuoles. Examples are seen in Fig. 2. As expected, cell survival following exposure to cisplatin varied between the SCC cell lines, with the more sensitive cell lines, LU-HNxSCC-7 and LU-HNxSCC-24, demonstrating a higher degree of cell death than the less sensitive cell line. The latter cell line, the LU-CX-2, was not affected by a cisplatin dose of $10 \mu \mathrm{M}$ (see Fig. 3).

\section{Cell cycle analysis}

With flow cytometry, we found that cisplatin exposure of the tumor cells resulted in an accumulation of cells in the S phase, and subsequent cell cycle arrest in the $G_{2} / M$ phase. This effect was observed on days 3 and 6 , and was more pronounced after the higher cisplatin dose. The untreated tumor cells showed a gradually increasing $G_{1}$ phase over time and no cell cycle arrest. For the fibroblasts, a brief and transient accumulation of cells in the $\mathrm{S}$ phase and in the $\mathrm{G}_{2} /$ $\mathrm{M}$ phase was observed after cisplatin exposure.

\section{Discussion}

In this study we have demonstrated that exposure to cisplatin causes a rise in metabolism in SCC cell lines compared with the pretreatment metabolism. This early metabolic flare precedes cell death and is clearly visualized with fluorescent 2-NBDG with real-time microscopy. A similar flare reaction after cisplatin exposure was observed by Aide and co-workers in a longitudinal study of testicular cancer xenografts evaluated in a micro-PET system with $\left[{ }^{18} \mathrm{~F}\right] \mathrm{FDG}$ at days $0,2,4$, and 7 . A transient metabolic flare on day 2 was found and this flare coincided with a rise in cyclin A and a temporary cell cycle arrest in S-and $\mathrm{G}_{2} / \mathrm{M}$ phase on flow cytometry. At day 7 the flare had subsided and the level of $\left[{ }^{18} \mathrm{~F}\right] \mathrm{FDG}$ uptake had decreased to below the pre-therapeutic level and correlated to cell death [8]. It is reasonable to believe that the pronounced sensitivity to cisplatin in testicular carcinomas may be the explanation for the large proportion of apoptotic cells as well as the preapoptotic peak the authors found in the cell cycle analysis. The cell lines in the present study had a lower sensitivity to cisplatin compared with a testicular cancer cell line, and the absence of a pre-apoptotic peak in our cell cycle analysis was thus not surprising. The accumulation of treated tumor cells in S- and G2/M-phase is in concordance with the study by Aide et al. [8]

Antitumor treatment causes cell death by various mechanisms. In the case of cisplatin, the most important factor is the induction of DNA damage and apoptosis [13]. Pre-apoptotic cells have an increased $\left[{ }^{18} \mathrm{~F}\right] \mathrm{FDG}$ metabolism compared with nondamaged cells [14], as the apoptotic process requires high amounts of adenosine-5'-triphosphate (ATP) [15]. The possibility of a passive influx of $\left[{ }^{18} \mathrm{~F}\right] \mathrm{FDG}$ over a damaged cell membrane cannot be ruled out, but this would also lead to a visual flare equally predictive of cell death. The explanatory model, where lethally damaged cells show a metabolic flare due to pre-apoptotic changes, is further supported by the fact that an early metabolic flare has also been identified following radiotherapy, albeit this is not an apoptotic cell death. Furuta et al. [16] investigated the $\left[{ }^{18} \mathrm{~F}\right]$ FDG accumulation in nude mice bearing ependymoblastoma, small cell lung cancer, and glioblastoma at 2 , 4 , and $6 \mathrm{~h}$ after a single radiotherapy dose of $10 \mathrm{~Gy}$. A transient flare in FDG-uptake was observed after $2 \mathrm{~h}$ in the 
Fig. 1 Fluorescence as a marker of 2-NBDG uptake over time after exposure to different doses of cisplatin. The results are relative within each cell line. Mean values and SEM are shown ( $A U$ arbitrary units)
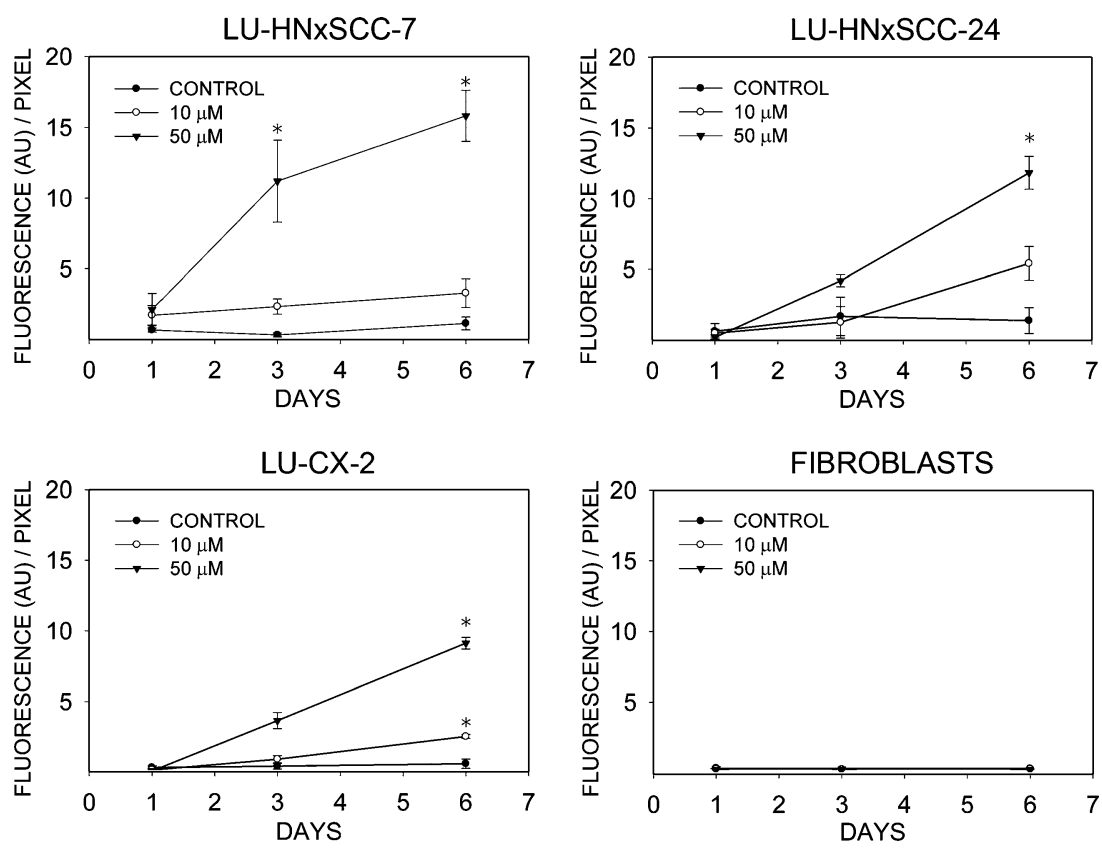

most radiosensitive of the tumors, the ependymoblastoma, whereas the less radiosensitive tumors showed no rise in $\left[{ }^{18} \mathrm{~F}\right]$ FDG uptake during the observation time. This corroborates the fact that the flare is more obvious where the treatment effect is stronger and thus may be an early predictive sign of treatment effect.

We undertook this study to elucidate early metabolic changes during cytotoxic therapy with predictive, ontherapy clinical studies in mind. Issues are often raised that false-positive findings due to reactive and inflammatory
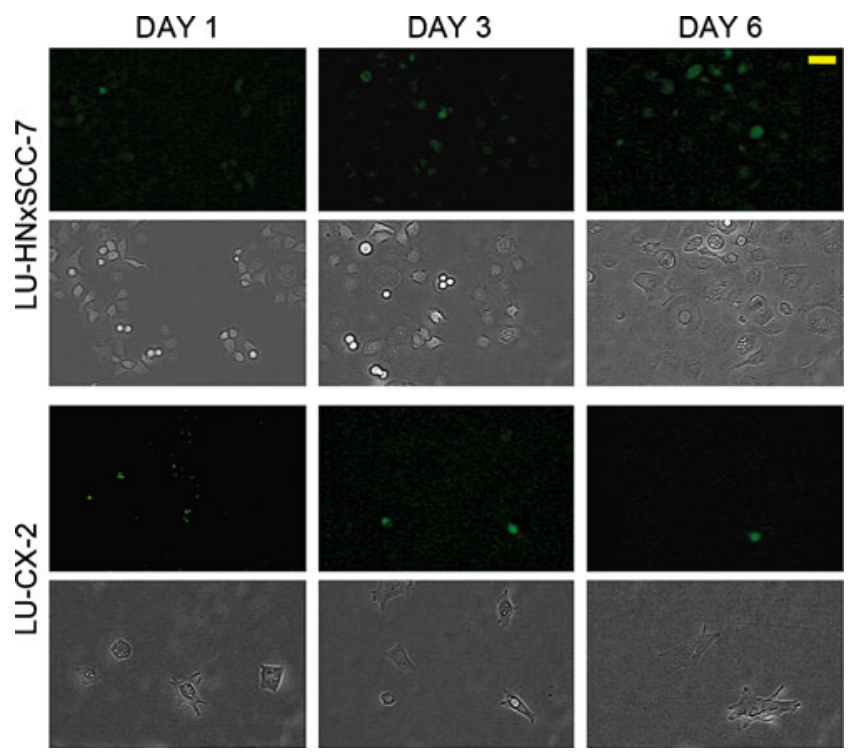

Fig. 2 Examples of visible flare over time. Fluorescence (top) and light (bottom) images of the cell lines LU-HNxSCC-7 and LU-CX-2 at days 1,3 , and 6 after exposure to $50 \mu \mathrm{M}$ cisplatin. A marked uptake of 2-NBDG was visible in pre-apoptotic cells. The bar at the top right indicates $10 \mu \mathrm{m}$ changes will lead to misjudgments in $\left[{ }^{18} \mathrm{~F}\right] \mathrm{FDG}-\mathrm{PET}$ studies carried out during or closely after therapy. The related fear of misinterpreting treatment results has led to recommendations that at least 6-12 weeks should elapse before post-treatment scans may be performed for therapy response assessment $[17,18]$. The discussion of glucose analogue uptake in surrounding tissue is of great interest. In their study on testicular cancer xenografts, Aide et al. [8] found a constant level of macrophage infiltration on days $0-4$, and thus the presence of reactive cells was not responsible for the observed metabolic flare which is also in agreement with our previous results from an HNSCC xenograft model subjected to cisplatin and investigated with phosphor imaging and histopathology at days 1, 2, 5, and 8 [10]. In the present study, the fibroblasts showed a consistent low uptake of 2-NBDG, suggesting that the tumor stroma is not a major source of hypermetabolism. Our findings are supported by data presented by Farace et al. [19], who observed in a study on xenografts of prostate

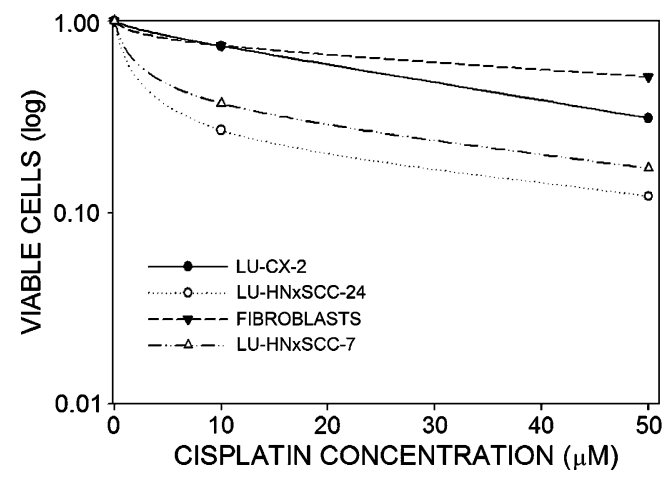

Fig. 3 Cell survival day 3 in relation to cisplatin 
and pancreatic cancer that the tumor stroma as well as the tumor cells adjacent to the stroma and adjacent to blood vessels exhibited a low $\left[{ }^{18} \mathrm{~F}\right] \mathrm{FDG}$ avidity.

Interestingly, not only a metabolic flare seems to occur early after cytotoxic treatment but also an increased rate of proliferation has been observed in responding tumors. Everitt et al. [20] reported the case of a patient with nonsmall cell lung cancer in which the tumor showed a flare of the proliferation marker $3^{\prime}$-deoxy- $3^{\prime}-\left[{ }^{18} \mathrm{~F}\right]$ fluoro-L-thymidine $\left(\left[{ }^{18} \mathrm{~F}\right] \mathrm{FLT}\right)$ after 2 Gy of radiotherapy. The flare was subsequently followed by a decrease in $\left[{ }^{18} \mathrm{~F}\right] \mathrm{FLT}$ uptake below the baseline level, interpreted as a sign of tumor response to treatment.

\section{Conclusion}

We have demonstrated a metabolic flare as an early sign, within days of response to cytotoxic treatment, as visualized with 2-NBDG uptake. Understanding the underlying biological properties of this flare will expand the knowledge of treatment response and sensitivity, and consequentially the interpretation of the $\left[{ }^{18}\right.$ F]FDG-PET scan. Potentially, it could thus be used as an early marker of treatment sensitivity.

Acknowledgements The authors wish to thank Christina Boll for technical assistance. This work was supported by the Foundations of the University Hospital of Lund, the Swedish Cancer Society (07 0833 and 07 0771), Governmental funding of clinical research within the NHS Region of Scania R\&D funding, Gunnar Nilssons Cancerstiftelse, and Fru Berta Kamprads Stiftelse för Utforskning och Bekämpning av Cancersjukdomar.

Open Access This article is distributed under the terms of the Creative Commons Attribution Noncommercial License which permits any noncommercial use, distribution, and reproduction in any medium, provided the original author(s) and source are credited.

\section{References}

1. Brun E, Kjellén E, Tennvall J, Ohlsson T, Sandell A, Perfekt R et al (2002) FDG PET studies during treatment: prediction of therapy outcome in head and neck squamous cell carcinoma. Head Neck 24:27-35

2. Hutchings M, Loft A, Hansen M, Pedersen LM, Buhl T, Jurlander $\mathrm{J}$ et al (2006) FDG-PET after two cycles of chemotherapy predicts treatment failure and progression-free survival in Hodgkin lymphoma. Blood 107:52-9

3. Ott K, Weber WA, Lordick F, Becker K, Busch R, Herrmann K et al (2006) Metabolic imaging predicts response, survival, and recurrence in adenocarcinomas of the esophagogastric junction. $\mathrm{J}$ Clin Oncol 24:4692-8

4. Bjurberg M, Kjellén E, Ohlsson T, Bendahl PO, Brun E (2009) Prediction of patient outcome with 2-deoxy-2-[18F]fluoro-Dglucose-positron emission tomography early during radiotherapy for locally advanced cervical cancer. Int J Gynecol Cancer 19:1600-5

5. Spaepen K, Stroobants S, Dupont P, Bormans G, Balzarini J, Verhoef $\mathrm{G}$ et al (2003) [(18)F]FDG PET monitoring of tumour response to chemotherapy: does [(18)F]FDG uptake correlate with the viable tumour cell fraction? Eur J Nucl Med Mol Imaging 30:682-8

6. Dehdashti F, Flanagan F, Mortimer JE, Katzenellenbogen JA, Welch MJ, Siegel BA (1999) Positron emission tomographic assessment of "metabolic flare" to predict response of metastatic breast cancer to antiestrogen therapy. Eur J Nucl Med 26:51-6

7. Mortimer JE, Dehdashti F, Siegel BA, Trinkaus K, Katzenellenbogen JA, Welch MJ (2001) Metabolic flare: indicator of hormone responsiveness in advanced breast cancer. J Clin Oncol 19:2797-803

8. Aide N, Poulain L, Briand M, Dutoit S, Allouche S, Labiche A et al (2009) Early evaluation of the effects of chemotherapy with longitudinal FDG small-animal PET in human testicular cancer xenografts: early flare response does not reflect refractory disease. Eur J Nucl Med Mol Imaging 36:396-405

9. Aliaga A, Rousseau JA, Cadorette J, Croteau E, van Lier JE, Lecomte $\mathrm{R}$ et al (2007) A small animal positron emission tomography study of the effect of chemotherapy and hormonal therapy on the uptake of 2-deoxy-2-[F-18]fluoro-D-glucose in murine models of breast cancer. Mol Imaging Biol 9:144-50

10. Bjurberg M, Henriksson E, Brun E, Ekblad L, Ohlsson T, Brun A et al (2009) Early changes in 2-deoxy-2-[18F]fluoro-D-glucose metabolism in squamous-cell carcinoma during chemotherapy in vivo and in vitro. Cancer Biother Radiopharm 24:327-32

11. Cheng Z, Levi J, Xiong Z, Gheysens O, Keren S, Chen X et al (2006) Near-infrared fluorescent deoxyglucose analogue for tumor optical imaging in cell culture and living mice. Bioconjug Chem 17:662-9

12. O'ñNeil RG, Wu L, Mullani N (2005) Uptake of a fluorescent deoxyglucose analog (2-NBDG) in tumor cells. Mol Imaging Biol $7: 388-92$

13. Gonzalez VM, Fuertes MA, Alonso C, Perez JM (2001) Is cisplatin-induced cell death always produced by apoptosis? Mol Pharmacol 59:657-63

14. Kubota R, Kubota K, Yamada S, Tada M, Ido T, Tamahashi N (1994) Active and passive mechanisms of [fluorine-18] fluorodeoxyglucose uptake by proliferating and prenecrotic cancer cells in vivo: a microautoradiographic study. J Nucl Med 35:1067-75

15. Eguchi Y, Shimizu S, Tsujimoto Y (1997) Intracellular ATP levels determine cell death fate by apoptosis or necrosis. Cancer Res $57: 1835-40$

16. Furuta M, Hasegawa M, Hayakawa K, Yamakawa M, Ishikawa H, Nonaka T et al (1997) Rapid rise in FDG uptake in an irradiated human tumour xenograft. Eur J Nucl Med 24:435-8

17. Kutler DI, Wong RJ, Schoder H, Kraus DH (2006) The current status of positron-emission tomography scanning in the evaluation and follow-up of patients with head and neck cancer. Curr Opin Otolaryngol Head Neck Surg 14:73-81

18. Weber WA (2005) Use of PET for monitoring cancer therapy and for predicting outcome. J Nucl Med 46:983-95

19. Farace P, D'Ambrosio D, Mergio F, Galiè M, Nanni C, Spinelli A et al (2009) Cancer-associated stroma affects FDG uptake in experimental carcinomas. Implications for FDG-PET delineation of radiotherapy target. Eur J Nucl Med Mol Imaging 36:616-23

20. Everitt S, Hicks RJ, Ball D, Kron K, Schneider-Kolsky M, Walter $\mathrm{T}$ et al (2009) Imaging cellular proliferation during chemoradiotherapy: a pilot study of serial $18 \mathrm{~F}-\mathrm{FLT}$ positron emission tomography/computed tomography imaging for non-small-cell lung cancer. Int J Radiat Oncol Biol Phys 75:1098-104 